\title{
Axillary artery cannulation reduces early embolic stroke and mortality after open arch repair with circulatory arrest
}

Jung-Hwan Kim, MD, Seung Hyun Lee, MD, PhD, Sak Lee, MD, PhD, Young-Nam Youn, MD, PhD, Kyung-Jong Yoo, MD, PhD, and Hyun-Chel Joo, MD, PhD

\section{ABSTRACT}

Objective: To evaluate the efficacy of axillary artery cannulation for early embolic stroke and operative mortality, we retrospectively compared the outcomes between patients with or without axillary artery cannulation during open aortic arch repair with circulatory arrest.

Methods: Between January 2004 and December 2017, 468 patients underwent open aortic arch repair with circulatory arrest using antegrade cerebral perfusion and were divided into 2 groups according to the site of arterial cannulation: the axillary artery (axillary group, $\mathrm{n}=352$ ) or another site (nonaxillary group, $\mathrm{n}=116$ ) groups. Embolic stroke was defined as a physician-diagnosed new postoperative neurologic deficit lasting more than 72 hours, generally confirmed by computed tomography or magnetic resonance imaging.

Results: After propensity score matching, the patients' characteristics were comparable between the groups ( $\mathrm{n}=116$ in each). The incidences of acute type A dissection, aortic rupture, shock, or emergency operation were similar between groups. The incidence of early embolic stroke was significantly lower in axillary group $(\mathrm{n}=3[2.6 \%]$ vs $\mathrm{n}=10[8.6 \%] ; P=.046)$. Also, 30-day mortality $(\mathrm{n}=3$ $[2.6 \%]$ vs $\mathrm{n}=10[8.6 \%] ; P=.046)$ and in-hospital mortality $(\mathrm{n}=3[2.6 \%]$ vs $\mathrm{n}=11[9.5 \%] ; P=.027)$ occurred significantly lower in the axillary group.

Conclusions: Axillary artery cannulation reduced the early embolic stroke and early mortality after open arch repair with circulatory arrest. Axillary artery cannulation as the arterial cannulation site during open arch repair with circulatory arrest may be helpful in preventing embolic stroke and reducing early mortality. (J Thorac Cardiovasc Surg 2020;159:772-8)

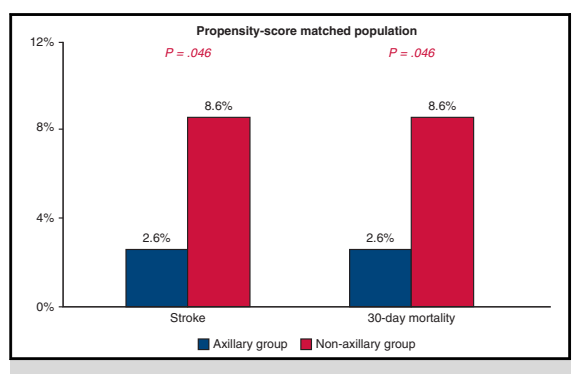

Incidences of stroke and 30-day mortality in axillary and nonaxillary groups.

\section{Central Message}

In patients undergoing open aortic arch repair with circulatory arrest using antegrade cerebral perfusion, axillary artery cannulation could reduce the early embolic stroke and early mortality.

\section{Perspective}

Despite the wide use of axillary artery cannulation, a general recommendation for the use of the axillary artery at the time of open aortic arch repair has not yet been advocated. This study evaluated the efficacy of axillary artery cannulation for early embolic stroke and operative mortality after open arch repair with circulatory arrest.

See Commentaries on pages 779 and 781 .
Open aortic arch repair with a combination of hypothermic circulatory arrest and antegrade cerebral perfusion (ACP) or retrograde cerebral perfusion is a well-established option

From the Division of Cardiovascular Surgery, Department of Thoracic and Cardiovascular Surgery, Severance Cardiovascular Hospital, Yonsei University College of Medicine, Seoul, Korea.

Received for publication June 18, 2018; revisions received Feb 13, 2019; accepted for publication Feb 24, 2019; available ahead of print April 13, 2019.

Address for reprints: Hyun-Chel Joo, MD, PhD, Severance Cardiovascular Hospital, Yonsei University College of Medicine, 250 Seongsanno, Seodaemun-gu, Seoul 03722, Republic of Korea (E-mail: vietcomm@yuhs.ac).

0022-5223

Copyright $($ C 2019 by The American Association for Thoracic Surgery. Published by Elsevier Inc. This is an open access article under the CC BY-NC-ND license (http:// creativecommons.org/licenses/by-nc-nd/4.0/).

https://doi.org/10.1016/j.jtcvs.2019.02.112 for various aortic pathologies with validated efficacy. ${ }^{1-4}$ However, postoperative neurologic complication is still a critical issue and among the major causes of morbidity and mortality after open arch repair.

The major cause of stroke after open arch surgery is embolism, rather than inadequate global cerebral protection. ${ }^{5,6}$ Most embolic strokes are caused by mobilization of aortic

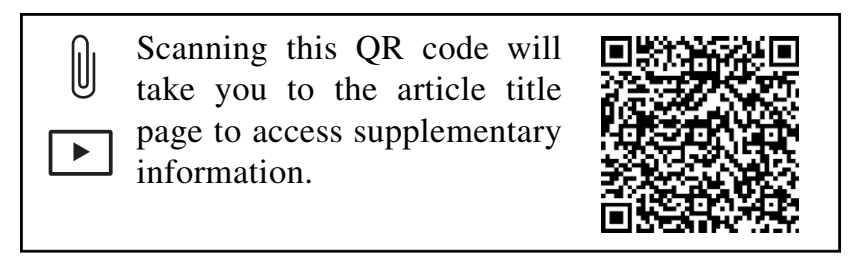




\section{Abbreviations and Acronyms \\ $\mathrm{ACP}=$ antegrade cerebral perfusion \\ $\mathrm{IQR}=$ interquartile range}

atheroma, which is associated with aortic manipulation and, more commonly, a sandblasting effect of the arterial jet that is derived from an inflow cannula. ${ }^{7}$ Therefore, a variety of cannulation strategies have been introduced, and evidence now suggests that axillary artery cannulation is more beneficial than other cannulation sites because it preserves antegrade flow in the aortic arch and descending aorta, thereby reducing the risk for embolization and facilitating the administration of selective antegrade cerebral perfusion during aortic arch repair. ${ }^{8-10}$ This also lowers the potential for embolization into right-sided cerebral vessels by perfusing them with a flow, which has not passed through the arch. ${ }^{8}$

These results led the authors of the 2014 European Society of Cardiology Guidelines on the Diagnosis and Treatment of Aortic Diseases to recommend that the axillary artery should be considered the first choice for cannulation for surgery of the aortic arch, including treatment of aortic dissection. ${ }^{11}$ Current reports also showed that the preferred first-choice arterial cannulation site was the axillary artery, regardless of the acuteness or aortic pathology. ${ }^{12}$ However, a general recommendation for the use of the axillary artery cannulation during aortic arch repair has not yet been advocated because of the lack of randomized trials and the insufficient level of evidence, and because the studies on this topic have had inconsistent inclusion criteria. ${ }^{13,14}$

To verify our hypothesis that the axillary artery cannulation might reduce the early embolic stroke and operative mortality, we retrospectively compared the outcomes between patients with or without axillary artery cannulation during open aortic arch repair with circulatory arrest.

\section{METHODS}

This retrospective study was approved by the institutional review board of Yonsei University Health System (institutional review board protocol No. 4-2018-0506). The requirement for patient consent was waived because courses of treatment were unchanged and the study database was designed to protect patient anonymity.

\section{Study Population}

Between January 2004 and December 2017, 511 patients underwent open aortic arch repair with circulatory arrest at our institution. Patients who received aortic arch repair concomitant with descending thoracic aorta or thoracoabdominal aorta repair using thoracotomy, hybrid aortic interventions such as arch stenting with arch vessels debranching, and salvage operation following cardiopulmonary resuscitation were excluded. Patients who were performed surgery with retrograde cerebral perfusion $(n=43)$ were also excluded and remaining 468 patients were enrolled in this study.

We divided the 468 patients into 2 groups according to the site of arterial cannulation: patients in whom the axillary artery was the site of cannulation (axillary group, $\mathrm{n}=352$ ), and those in which other sites were used for cannulation (nonaxillary group, $\mathrm{n}=116$ ). In the axillary group, arterial inflow cannulation sites included the right axillary artery alone $(\mathrm{n}=177[50 \%])$, the axillary artery with the femoral artery $(n=152[43 \%])$, and the axillary artery with the ascending aorta $(\mathrm{n}=23[7 \%])$. In the nonaxillary group, they included the femoral artery $(\mathrm{n}=63[54 \%])$ and ascending aorta $(\mathrm{n}=53[46 \%])$ (Figure 1, A).

\section{Technique for Axillary Artery Cannulation}

Arterial pressure was routinely measured at a right radial artery. After the median sternotomy, with the patient in a supine position, a transverse skin incision was made below the middle and lateral part of the right clavicle. A pectoralis major muscle was separated, and the axillary artery was identified by palpation and then gently dissected and mobilized. The axillary artery was defined as that part beyond the outer edge of the first rib. The artery was then controlled with loops of elastomer tape. After the administration of heparin, the axillary artery was clamped both proximally and distally with vessel clamps and a transverse arteriotomy was carried out. Then, an 8-mm tube graft was anastomosed to the axillary artery and the arterial cannula was anchored to the graft using several ties of silk (Video 1). Our cannulation strategy over time is summarized in Figure E1.

\section{Technique for Cerebral Perfusion}

All patients were monitored with simultaneous right radial and femoral arterial pressure lines, bilateral brain near infrared spectroscopy, and nasopharyngeal and bladder temperature probes. During circulatory arrest, patients in the axillary group experienced continuous cerebral perfusion with cold blood $\left(22^{\circ} \mathrm{C}-25^{\circ} \mathrm{C}\right)$ at a flow rate of 10 to $12 \mathrm{~mL} / \mathrm{kg} / \mathrm{min}$ to reach a target right radial arterial pressure of 50 to $70 \mathrm{~mm} \mathrm{Hg}$ using the axillary artery. Unilateral ACP was the selected initial strategy in all patients, with the option of adding the use of a left carotid perfusion cannula based on the near infrared spectroscopy monitoring. Use of unilateral ACP or bilateral ACP based on the near infrared spectroscopy monitoring was decided by surgeon preference in both axillary and nonaxillary groups.

\section{Data Collection and Outcome Measurements}

Preoperative data, perioperative data, and postoperative early outcomes were collected by reviewing medical records. The primary study end point was postoperative early embolic stroke, and the secondary end points were in-hospital mortality and major operative complications (ie, seizure, reoperation for bleeding, newly required dialysis, prolonged intubation [ $>48$ hours] or tracheostomy, deep sternal wound infection, and sepsis).

Embolic stroke was defined as a physician-diagnosed new postoperative neurologic deficit lasting more than 72 hours, generally confirmed by computed tomography or magnetic resonance imaging, occurring during hospitalization or within 30 days of surgery. This was included only in cases of an embolic cause, and not hypoxic brain damage caused by intraoperative cerebral hypoperfusion, pre- or postoperative shock. Hypoxic brain damage was distinguished from embolic stroke by diffuse brain hypoxia that was not correlated with cerebral artery territories. Right- or left-side stroke was defined as stroke that involved only the right or left hemispheres, respectively, and right-side involvement stroke was defined as all strokes that involved the right hemisphere, including those involving only the right side or both hemispheres. All embolic stroke, hypoxic brain damage, and the affected hemisphere were diagnosed by a radiologist and neurologist after reviewing computed tomography or magnetic resonance imaging.

\section{Statistical Analysis}

All data were expressed as the mean \pm standard deviation or frequency and percentage. Shapiro-Wilk test was used for normality test. If continuous variables were not normally distributed, they were expressed as median and interquartile range (IQR). Continuous variables were compared 

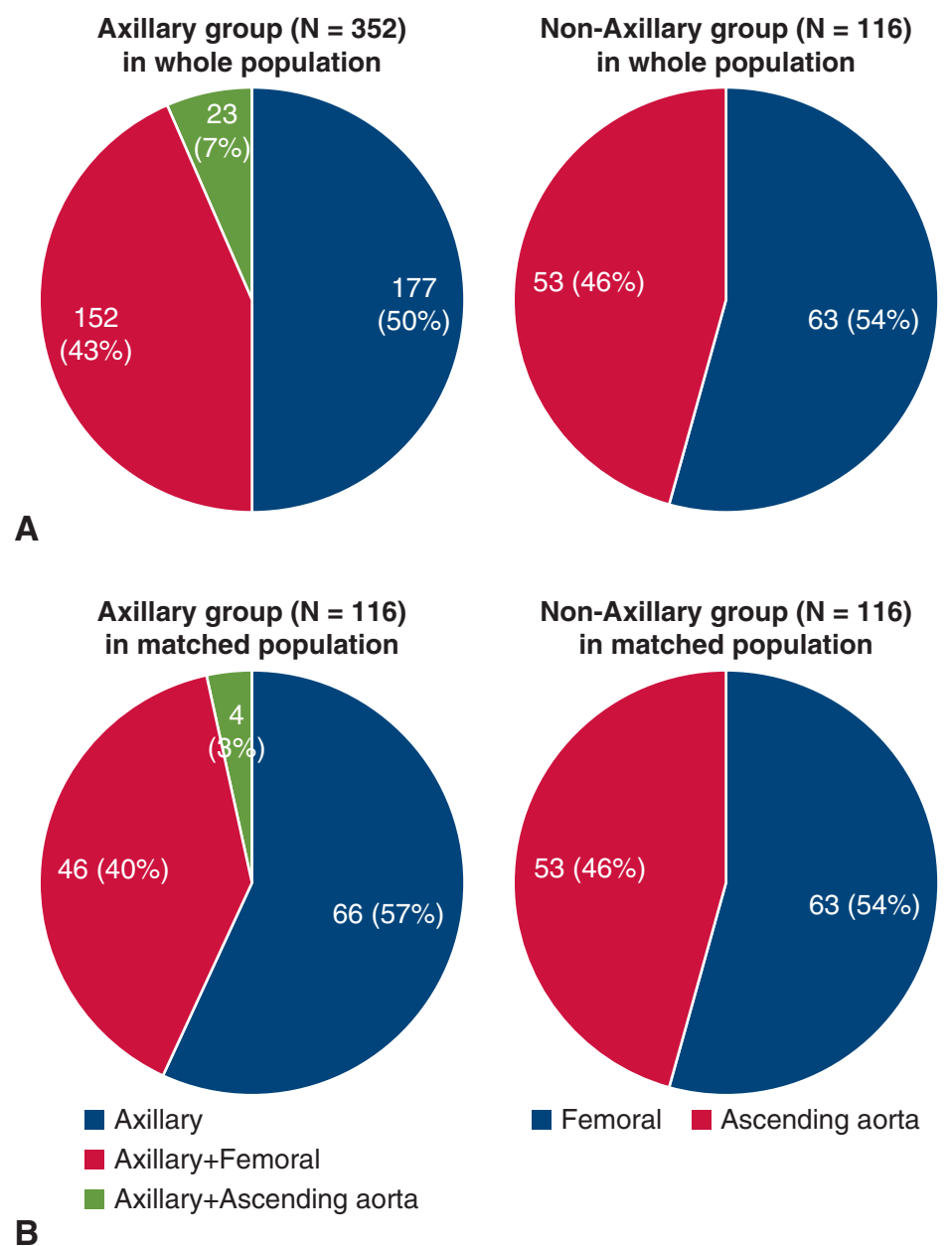

FIGURE 1. Arterial cannulation sites. A, Prematched population. B, Matched population.

using the Student $t$ test, applying Pearson $\chi^{2}$ test or Fisher exact test for categorical variables. If continuous variables were not normally distributed, Mann-Whitney test was used for comparing the continuous variables.

To balance the baseline characteristics between groups, a propensity score matching technique was used. Both groups were matched in a 1:1

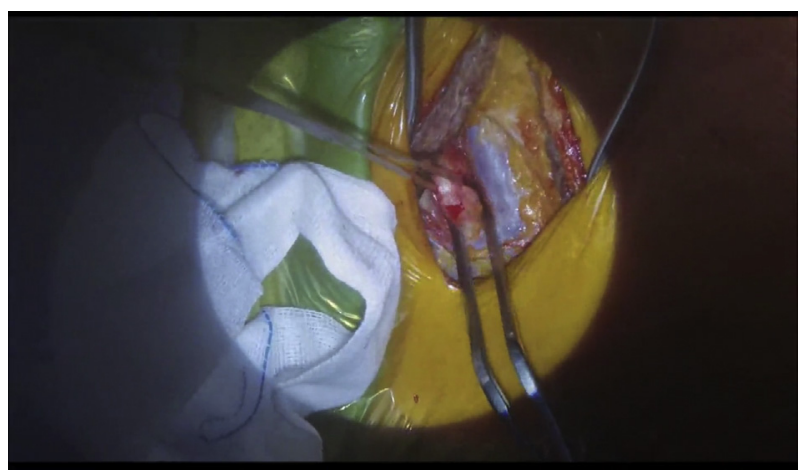

VIDEO 1. Surgical procedure of axillary artery cannulation. Video available at: https://www.jtcvs.org/article/S0022-5223(19)30590-2/fulltext. ratio based on the propensity score. By using propensity score matching, 116 patients in the axillary group were propensity matched to 116 patients in the nonaxillary group. The matching was well calibrated (Hosmer-Lemeshow goodness-of-fit $\chi^{2}, 0.812 ; P=.852$ ). Detailed description of propensity score matching is summarized in Figure E2. For the matched groups, means were compared using the paired Student $t$ test, and frequencies were compared using the McNemar test. If continuous variables were not normally distributed in matched groups, Wilcoxon signed-rank test was used for comparing the continuous variables. The analyses used standard software (SPSS version 22.0 for Windows; IBM-SPSS Inc, Armonk, NY), setting the significance at $P<.05$.

\section{RESULTS}

The median age was 65.0 years (IQR, 54.0-73.0 years) in the axillary group and 62.5 years (IQR, 51.3-71.0 years) in the nonaxillary group $(P=.128)$. The baseline characteristics of the 2 groups were different: the axillary group more likely to have hypertension, coronary artery occlusive disease, chronic obstructive pulmonary disease, and Debakey type I aortic dissection and had larger aortic arch diameter. The nonaxillary group had more incidence of preoperative shock status; experienced mental changes, required 
TABLE 1. Baseline characteristics in propensity score matched population

\begin{tabular}{|c|c|c|c|}
\hline Variable & $\begin{array}{c}\text { Axillary } \\
\text { group } \\
(\mathrm{n}=116)\end{array}$ & $\begin{array}{l}\text { Nonaxillary } \\
\text { group } \\
(\mathbf{n}=116) \\
\end{array}$ & SMD \\
\hline Age (y) & $62.5(50.0-70.8)$ & $62.5(51.3-71.0)$ & 0.021 \\
\hline Male sex & $60(51.7)$ & $63(54.3)$ & 0.069 \\
\hline $\operatorname{BSA}\left(\mathrm{m}^{2}\right)$ & $1.72(1.59-1.87)$ & $1.72(1.60-1.86)$ & 0.057 \\
\hline HTN & $69(59.5)$ & $70(60.3)$ & 0.035 \\
\hline DM & $10(8.6)$ & $12(10.3)$ & 0.059 \\
\hline CKD & $16(13.8)$ & $18(15.5)$ & 0.049 \\
\hline Dialysis & $1(0.9)$ & $2(1.7)$ & 0.076 \\
\hline Dyslipidemia & $4(3.4)$ & $4(3.4)$ & $<0.001$ \\
\hline CVA & 13 (11.2) & 15 (12.9) & 0.080 \\
\hline CAOD & $15(12.9)$ & 17 (14.7) & 0.050 \\
\hline COPD & $10(8.6)$ & $10(8.6)$ & $<0.001$ \\
\hline PAOD & $2(1.7)$ & $2(1.7)$ & $<0.001$ \\
\hline Carotid disease & $16(13.8)$ & $14(12.1)$ & 0.026 \\
\hline Previous OHS & $12(10.3)$ & $10(8.6)$ & 0.059 \\
\hline Marfan SD & $7(6.0)$ & $5(4.3)$ & 0.078 \\
\hline $\begin{array}{l}\text { EKG } \\
\text { Sinus } \\
\text { Afib } \\
\text { PM }\end{array}$ & $\begin{array}{c}107(92.2) \\
9(7.8) \\
0(0.0)\end{array}$ & $\begin{array}{c}110(94.8) \\
4(3.4) \\
2(1.7)\end{array}$ & 0.029 \\
\hline Acute TAD & $41(35.3)$ & $43(37.1)$ & 0.036 \\
\hline $\begin{array}{c}\text { Chronic aneurysm } \\
\text { Atherosclerosis } \\
\text { Postdissection }\end{array}$ & $\begin{array}{l}75(64.7) \\
62(82.7) \\
13(17.3)\end{array}$ & $\begin{array}{l}75(64.7) \\
61(81.3) \\
14(18.7)\end{array}$ & $\begin{array}{l}0.036 \\
0.025 \\
0.025\end{array}$ \\
\hline Shock & $11(9.5)$ & $13(11.2)$ & 0.056 \\
\hline Rupture & $5(4.3)$ & $7(6.0)$ & 0.078 \\
\hline $\begin{array}{l}\text { DeBakey type } \\
\text { I } \\
\text { II }\end{array}$ & $\begin{array}{l}41(35.3) \\
75(64.7)\end{array}$ & $\begin{array}{l}42(36.2) \\
74(63.8)\end{array}$ & 0.018 \\
\hline AA diameter (mm) & $50.0(46.3-58.0)$ & $51.5(47.0-57.8)$ & 0.039 \\
\hline Arch diameter $(\mathrm{mm})$ & $39.5(35.0-42.0)$ & $40.0(34.0-44.0)$ & 0.034 \\
\hline LVEF (\%) & $61.5(57.0-69.0)$ & $61.0(58.0-67.0)$ & 0.045 \\
\hline $\begin{array}{r}\text { Surgery year } \\
2004-2009 \\
2010-2014 \\
2015-2017\end{array}$ & $\begin{array}{l}21(18.1) \\
37(31.9) \\
58(50.0)\end{array}$ & $\begin{array}{l}28(24.1) \\
30(25.9) \\
58(50.0)\end{array}$ & 0.076 \\
\hline
\end{tabular}

Values for continuous variables are presented as median (interquartile range) and values for categorical variables presented as $\mathrm{n}(\%)$. SMD, Standardized mean difference; $B S A$, body surface area; $H T N$, hypertension; $D M$, diabetes mellitus; $C K D$, chronic kidney disease; $C V A$, cerebrovascular accident; $C A O D$, coronary artery occlusive disease; $C O P D$, chronic obstructive pulmonary disease; $P A O D$, peripheral artery occlusive disease; $O H S$, open heart surgery; $S D$, syndrome; $E K G$, electrocardiogram; Afib, atrial fibrillation; $P M$, pacemaker; $T A D$, type A dissection; $A A$, ascending aorta; $L V E F$, left ventricular ejection fraction.

intubation, had systolic blood pressure $<90 \mathrm{~mm} \mathrm{Hg}$, or require vasopressors to maintain systolic blood pressure $\geq 90 \mathrm{~mm} \mathrm{Hg}$. After propensity score matching, the
TABLE 2. Operative data in propensity score matched population

\begin{tabular}{|c|c|c|c|}
\hline Variable & $\begin{array}{c}\text { Axillary } \\
\text { group } \\
(n=116)\end{array}$ & $\begin{array}{l}\text { Nonaxillary } \\
\text { group } \\
(\mathbf{n}=116)\end{array}$ & SMD \\
\hline Emergency & 37 (31.9) & $41(35.3)$ & 0.066 \\
\hline \multicolumn{4}{|l|}{$\begin{array}{l}\text { Concomitant } \\
\text { operation }\end{array}$} \\
\hline AVR & $47(40.5)$ & 37 (31.9) & 0.144 \\
\hline AV repair & 25 (21.6) & $20(17.2)$ & 0.103 \\
\hline Root replacement & $14(12.1)$ & $21(18.1)$ & 0.172 \\
\hline CABG & $12(10.3)$ & $8(6.9)$ & 0.121 \\
\hline Mitral surgery & $1(0.9)$ & $4(3.4)$ & 0.138 \\
\hline Tricuspid surgery & $2(1.7)$ & $4(3.4)$ & 0.038 \\
\hline Others & $2(1.7)$ & $4(3.4)$ & $<0.001$ \\
\hline \multicolumn{4}{|l|}{ Type of surgery } \\
\hline Hemiarch & 89 (76.7) & $97(83.6)$ & 0.096 \\
\hline Partial arch & $4(3.4)$ & $6(5.2)$ & 0.057 \\
\hline Total arch & $23(19.8)$ & 13 (11.2) & 0.146 \\
\hline Unilateral ACP & $34(29.3)$ & $33(28.4)$ & 0.051 \\
\hline CPB time (min) & $155.0(126.0-190.0)$ & $156.0(119.0-212.0)$ & 0.014 \\
\hline ACC time (min) & $104.0(85.0-125.0)$ & $105.0(79.0-136.5)$ & 0.047 \\
\hline TCA time (min) & $25.5(17.0-41.5)$ & $20.0(14.0-34.0)$ & 0.190 \\
\hline $\begin{array}{l}\text { Moderate } \\
\text { hypothermia }\end{array}$ & $111(95.7)$ & $109(94.0)$ & 0.049 \\
\hline Lowest BT $\left({ }^{\circ} \mathrm{C}\right)$ & $28.0(27.3-29.5)$ & $28.0(26.0-28.8)$ & 0.086 \\
\hline
\end{tabular}

demographic characteristics of the 2 groups $(n=116$ in each) were comparable. Arterial cannulation sites after propensity score matching were descripted in Figure 1, $B$. The patients' baseline characteristics are summarized in Table 1 for the propensity-matched population and Table E1 for the unmatched population.

In the propensity score matched population, 37 patients $(31.9 \%)$ in the axillary group and 41 patients $(35.3 \%)$ in the nonaxillary group underwent emergent surgery $(P=.578)$. Total arch replacement was performed more in the axillary group, whereas hemiarch replacement was performed more in the nonaxillary group, but the difference was not statistically significant $(P=.172)$. Unilateral ACP was used for 34 patients $(29.3 \%)$ in the axillary group and for 33 patients $(28.4 \%)$ in the nonaxillary group $(P=.891)$. Cardiopulmonary bypass time and aorta crossclamp time were similar between the groups, but total circulatory arrest time was significantly longer in axillary group $(25.5 \mathrm{mi}-$ nutes; IQR, 17.0-41.5 minutes vs 20.0 minutes; IQR, 14.0-34.0 minutes; $P=.014)$. Circulatory arrest was performed under moderate hypothermia $\left(20^{\circ} \mathrm{C}-28^{\circ} \mathrm{C}\right)$ in most of the cases $(94.8 \%)$, and the rate of moderate hypothermia 


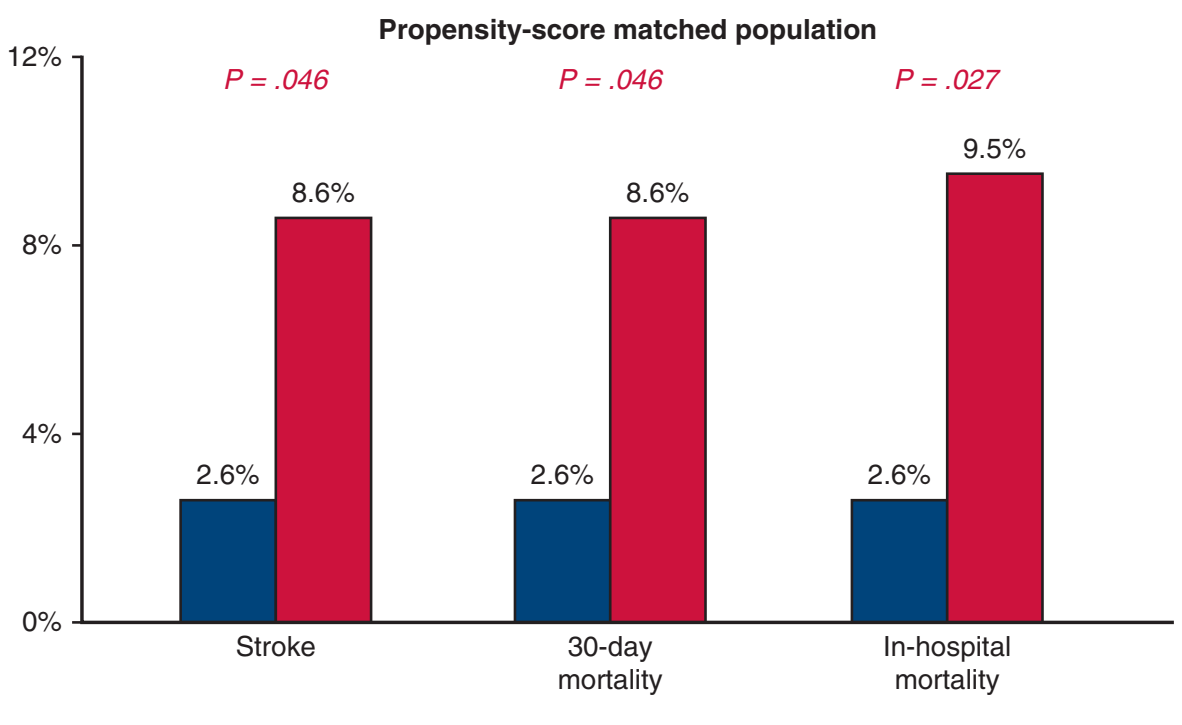

Axillary group $\square$ Non-axillary group

FIGURE 2. The incidence of embolic stroke, 30-day mortality, and in-hospital mortality in the axillary group and nonaxillary group. All end points were significantly lower in the axillary group.

and lowest bladder temperature were similar in both groups (Table 2).

\section{Embolic Stroke}

In the entire population, early embolic stroke occurred in 22 patients $(4.7 \%)$. In the propensity score matched population, the axillary group showed significantly lower incidence of stroke $(\mathrm{n}=3[2.6 \%]$ vs $\mathrm{n}=10[8.6 \%]$; $P=.046$ ) (Figure 2). Right-side involvement stroke occurred significantly more in the nonaxillary group $(\mathrm{n}=2[1.7 \%]$ vs $\mathrm{n}=10[8.6 \%] ; P=.018)$. Seizure that was not accompanied with embolic stroke also occurred significantly more in the nonaxillary group $(\mathrm{n}=2[1.7 \%]$ vs $\mathrm{n}=12[10.3 \%] ; P=.006)$ (Table 3 ).

\section{Operative Death and Early Complications}

During the hospitalization period, 29 patients $(6.2 \%)$ died. In-hospital mortality had tended to decrease over time (Figure E3). In the propensity score matched population, 30-day mortality was significantly lower in the axillary group than in the nonaxillary group $(\mathrm{n}=3[2.6 \%]$ vs $\mathrm{n}=10$ [8.6\%]; $P=.046)$. In-hospital mortality was also significantly lower in the axillary group $(\mathrm{n}=3[2.6 \%]$ vs $\mathrm{n}=11[9.5 \%] ; P=.027$ ) (Figure 2). The incidence of newly required dialysis and prolonged mechanical ventilation ( $>48$ hours) were significantly higher in nonaxillary group (Table 3$)$.

\section{DISCUSSION}

In this observational study, we compared different cannulation strategies for open arch repair and found that axillary artery cannulation reduced the incidence of early embolic stroke and early mortality compared with femoral artery and ascending aorta cannulation. During the past 2 decades, studies with large numbers of patients have reported the incidence of stroke after open arch repair was approximately $5 \%,{ }^{1,15}$ and the outcome has been dramatically improved by innovations in surgical techniques, including brain protection. The widespread use of hypothermic circulatory arrest and selective ACP for cerebral

TABLE 3. Early outcomes in propensity score matched population

\begin{tabular}{|c|c|c|c|}
\hline Variable & $\begin{array}{c}\text { Axillary } \\
\text { group } \\
(n=116)\end{array}$ & $\begin{array}{c}\text { Nonaxillary } \\
\text { group } \\
(\mathbf{n}=116)\end{array}$ & $P$ value \\
\hline Stroke & $3(2.6)$ & $10(8.6)$ & .046 \\
\hline Right & $2(1.7)$ & $5(4.3)$ & .446 \\
\hline Left & $1(0.9)$ & $0(0.0)$ & $>.999$ \\
\hline Both & $0(0.0)$ & $5(4.3)$ & .060 \\
\hline Right side involvement & $2(1.7)$ & $10(8.6)$ & .018 \\
\hline Seizure & $2(1.7)$ & $12(10.3)$ & .006 \\
\hline Reoperation for bleeding & $8(6.9)$ & $12(10.3)$ & .349 \\
\hline Newly required dialysis & $4(3.4)$ & $13(11.2)$ & .023 \\
\hline Prolonged intubation & $16(13.8)$ & $32(27.6)$ & .010 \\
\hline Deep sternal infection & $0(0.0)$ & $2(1.7)$ & .498 \\
\hline Sepsis & $2(1.7)$ & $3(2.6)$ & $>.999$ \\
\hline Intensive care unit stay (d) & $2.0(2.0-3.0)$ & $2.0(2.0-7.0)$ & .005 \\
\hline Hospital stay (d) & $11.0(8.3-17.0)$ & $13.0(8.3-25.0)$ & .075 \\
\hline 30-d mortality & $3(2.6)$ & $10(8.6)$ & .046 \\
\hline In-hospital mortality & $3(2.6)$ & $11(9.5)$ & .027 \\
\hline
\end{tabular}

Values for continuous variables are presented as median (interquartile range) and values for categorical variables are presented as $n(\%)$. 
protection has contributed to the reduction in mortality and stroke rates. ${ }^{16,17}$ Because of these technical advances to prevent cerebral hypoperfusion during circulatory arrest, the major cause of stroke after open arch repair is embolism. ${ }^{5,6}$ Ergin and colleagues ${ }^{18}$ concluded that permanent neurologic deficits were due to thromboembolic events and were not related to the type of cerebral protection used. Most embolic strokes during open arch repair are caused by mobilization of aortic atheroma, which is associated with aortic manipulation or retrograde flow from the lower body, and more commonly, by a sandblasting effect of the arterial jet that is derived from an arterial cannula. Therefore, femoral artery cannulation without additional antegrade flow in a severely atherosclerotic and diseased aorta enhances the potential for embolization into the cerebral circulation, producing neurologic injury. ${ }^{19,20}$ In addition, because of the sandblasting effect, the ascending aorta cannulation causes damage to the aortic wall and dislodging of atheroemboli that increases the risk of embolic stroke (Figure 3).

In the past, several studies have demonstrated the advantage of axillary cannulation in terms of stroke reduction in atherosclerotic aortic disease. ${ }^{21,22}$ Besides atherosclerotic aneurysm, there were several reports, including metaanalyses, that axillary artery cannulation was superior to femoral artery cannulation in reducing the incidence of stroke in patients with acute type A aortic dissection. ${ }^{9,23,24}$ Wada and colleagues ${ }^{25}$ reported the pathologic characteristics of aortic dissection, and they found that $44.4 \%$ of aortic

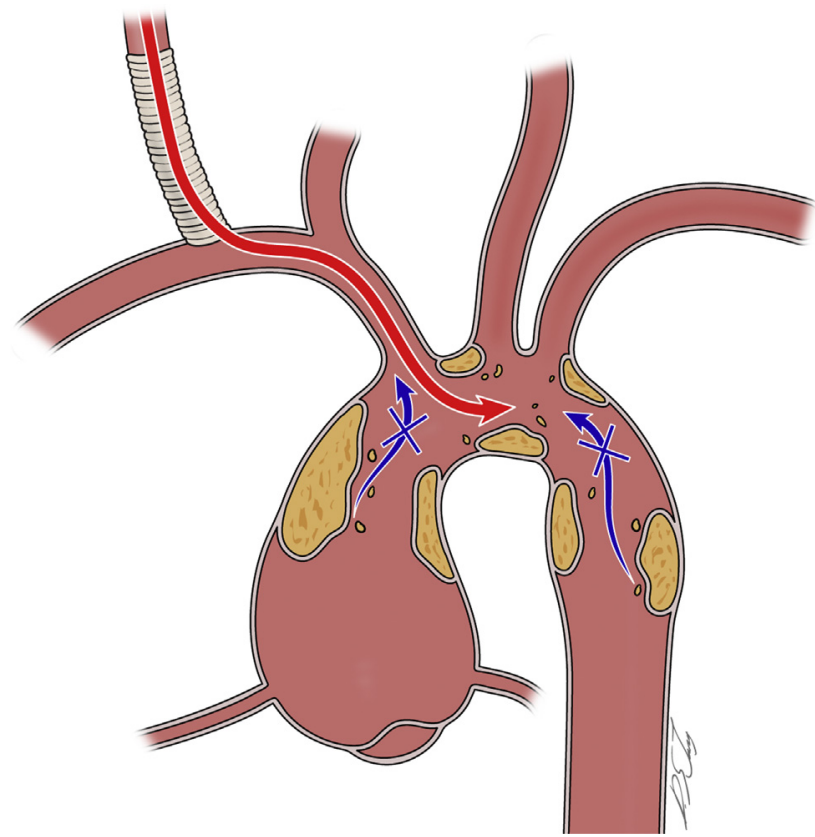

FIGURE 3. Mechanism of preventing embolic stroke of axillary artery cannulation during open arch repair. Continuous antegrade flow of axillary artery cannulation can prevent the retrograde embolism from the distal aorta and sandblasting effect from the ascending aorta. dissections had preatheromatous lesions and 55.6\% had atheromatous plaques. Moreover, a thrombus was found in most $(85.2 \%)$ of the false lumens in patients with aortic dissection. Therefore, axillary cannulation also has potential advantages in reducing embolic stroke caused by retrograde embolization and disruption of the atheroma or calcified plaques of femoral cannulation, as well as reducing the risk of false lumen perfusion and postoperative ischemia due to malperfusion.

Our study also found that the incidence of right-side hemisphere stroke was significantly lower in the axillary artery cannulation group. Hemispheric distribution of stroke and subsequent outcomes after open arch repair and the mechanistic distinction between bilateral and unilateral stroke are not fully understood. A possible mechanism is that the continuous antegrade flow from the right axillary artery prevents the embolism from the ascending aorta and retrograde flow of the femoral artery cannulation. Hedberg and colleagues ${ }^{26}$ reported early stroke after cardiac surgery was more common in the right rather than the left hemisphere, whereas delayed stroke had a uniform distribution. Individuals with bilateral lesions showed lower survival than those with unilateral lesions, but there was no survival difference between left- and right-hemisphere stroke. Our study did not demonstrate a relationship between hemispheric distribution of stroke and subsequent survival; however, patients with stroke involving the right hemisphere showed a higher tendency of prolonged mechanical ventilation ( $>48$ hours) $(68.4 \%$ vs $50.0 \% ; P=.630)$ and prolonged hospital stay ( $>14$ days) $(53.8 \pm 45.1$ days vs $47.7 \pm 51.9$ days; $P=.782$ ), which was not statistically significant. Further studies should be performed to identify the influence of hemispheric distribution of stroke and subsequent clinical outcomes.

In-hospital mortality was significantly lower in the axillary cannulation group. Stroke itself did not show a direct correlation with mortality, but associated complications, such as prolonged mechanical ventilation or acute kidney injury requiring dialysis, adversely influenced early mortality. In our study, the incidence of seizure, newly required dialysis, and prolonged mechanical ventilation were significantly higher in the nonaxillary group. Etz and colleagues $^{22}$ also reported a survival benefit of axillary cannulation, and they explained that the reason was the superior brain protection of axillary artery cannulation from embolism, thus reducing neurologic injury.

This study was limited by its retrospective nature. There were differences in patients' characteristics between the axillary and nonaxillary groups, and there was heterogeneity of aorta pathology, and the type of arch repair. To adjust the risk factors and reduce selection bias, we used propensity score matching, but selection bias or unidentified confounding bias may influence the results despite the propensity-matched comparison. Another important 
limitation of this study was that we did not compare the patients who were used only axillary artery and ascending aorta or only axillary artery and femoral artery. The sample size becomes too low in such categorization, and it made statistical power become too weak to come up with the statistically sufficient results. We did not analyze long-term outcomes, only the early clinical outcomes. Long-term stroke is caused by a variety of factors, so early stroke should be analyzed to identify the impact of arterial cannulation strategies for embolic stroke. And we do not have data measuring the flow distribution according to the cannulation site. The number of enrolled patients were relatively small and about two thirds of patients in axillary group were dropped out after propensity score matching. Finally, we only included symptomatic stroke and there might be a possibility that asymptomatic or subclinical stroke was left off this study. However, it was known that subclinical central nervous system injuries are not associated with in-hospital outcomes. $^{27}$

\section{CONCLUSIONS}

Right axillary artery cannulation reduced the rate of early embolic stroke and early mortality, including in-hospital and 30-day mortality after open arch repair with circulatory arrest using ACP. Axillary artery cannulation as the arterial cannulation site during open arch repair with circulatory arrest may be helpful in preventing embolic stroke and reducing early mortality.

\section{Conflict of Interest Statement}

Authors have nothing to disclose in regard to commercial support.

The authors thank Dong-Su Jang, MFA, for his help with the illustrations.

\section{References}

1. Patel HJ, Nguyen C, Diener AC, Passow MC, Salata D, Deeb GM. Open arch reconstruction in the endovascular era: analysis of 721 patients over 17 years. J Thorac Cardiovasc Surg. 2011;141:1417-23.

2. Zierer A, El-Sayed Ahmad A, Papadopoulos N, Moritz A, Diegeler A, Urbanski PP. Selective antegrade cerebral perfusion and mild $\left(28^{\circ} \mathrm{C}-30^{\circ} \mathrm{C}\right)$ systemic hypothermic circulatory arrest for aortic arch replacement: results from 1002 patients. J Thorac Cardiovasc Surg. 2012;144:1042-9.

3. Okada K, Omura A, Kano H, Sakamoto T, Tanaka A, Inoue T, et al. Recent advancements of total aortic arch replacement. J Thorac Cardiovasc Surg. 2012; 144:139-45.

4. Thomas M, Li Z, Cook DJ, Greason KL, Sundt TM. Contemporary results of open aortic arch surgery. J Thorac Cardiovasc Surg. 2012;144:838-44.

5. Imasaka K, Tayama E, Tomita Y. The impact of carotid and/or intracranial atherosclerosis on perioperative stroke in patients undergoing open aortic arch surgery. J Thorac Cardiovasc Surg. 2017;153:1045-53.

6. Goldstein LJ, Davies RR, Rizzo JA, Davila JJ, Cooperberg MR, Shaw RK, et al Stroke in surgery of the thoracic aorta: incidence, impact, etiology, and prevention. J Thorac Cardiovasc Surg. 2001;122:935-45.

7. Shiiya N. Aortic arch replacement for degenerative aneurysms: advances during the last decade. Gen Thorac Cardiovasc Surg. 2013;61:191-6.
8. Strauch JT, Spielvogel D, Lauten A, Lansman SL, McMurtry K, Bodian CA, et al. Axillary artery cannulation: routine use in ascending aorta and aortic arch replacement. Ann Thorac Surg. 2004;78:103-8.

9. Benedetto U, Mohamed H, Vitulli P, Petrou M. Axillary versus femoral arterial cannulation in type A acute aortic dissection: evidence from a meta-analysis of comparative studies and adjusted risk estimates. Eur J Cardiothorac Surg. 2015;48:953-9.

10. Ren Z, Wang Z, Hu R, Wu H, Deng H, Zhou Z, et al. Which cannulation (axillary cannulation or femoral cannulation) is better for acute type A aortic dissection repair? A meta-analysis of nine clinical studies. Eur J Cardiothorac Surg. 2015;47:408-15.

11. Erbel R, Aboyans V, Boileau C, Bossone E, Bartolomeo RD, Eggebrecht H, et al. 2014 ESC Guidelines on the diagnosis and treatment of aortic diseases: document covering acute and chronic aortic diseases of the thoracic and abdominal aorta of the adult. The task force for the diagnosis and treatment of aortic diseases of the European Society of Cardiology (ESC). Eur Heart J. 2014;35:2873-926.

12. Chalegre ST, Sá MP, de Rueda FG, Salerno PR, Vasconcelos FP, Lima RC. Central versus peripheral arterial cannulation and neurological outcomes after thoracic aortic surgery: meta-analysis and meta-regression of 4459 patients. Perfusion. 2015;30:383-8.

13. Di Eusanio M, Pantaleo A, Petridis FD, Folesani G, Cefarelli M, Berretta P, et al. Impact of different cannulation strategies on in-hospital outcomes of aortic arch surgery: a propensity-score analysis. Ann Thorac Surg. 2013;96:1656-63.

14. De Paulis R, Czerny M, Weltert L, Bavaria J, Borger MA, Carrel TP, et al. Current trends in cannulation and neuroprotection during surgery of the aortic arch in Europe. Eur J Cardiothorac Surg. 2015;47:917-23.

15. Iba Y, Minatoya K, Matsuda H, Sasaki H, Tanaka H, Kobayashi J, et al. Contemporary open aortic arch repair with selective cerebral perfusion in the era of endovascular aortic repair. J Thorac Cardiovasc Surg. 2013;145:S72-7.

16. Kazui T, Yamashita K, Washiyama N, Terada H, Bashar AH, Suzuki K, et al. Aortic arch replacement using selective cerebral perfusion. Ann Thorac Surg. 2007;83:S796-8.

17. Zierer A, Detho F, Dzemali O, Aybek T, Moritz A, Bakhtiary F. Antegrade cerebral perfusion with mild hypothermia for aortic arch replacement: single-center experience in 245 consecutive patients. Ann Thorac Surg. 2011;91:1868-74.

18. Ergin MA, Galla JD, Lansman SL, Quintana C, Bodian C, Griepp RB. Hypothermic circulatory arrest in operations on the thoracic aorta. Determinants of operative mortality and neurologic outcome. J Thorac Cardiovasc Surg. 1994;107: 788-99.

19. Sabik JF, Lytle BW, McCarthy PM, Cosgrove DM. Axillary artery: an alternative site of arterial cannulation for patients with extensive aortic and peripheral vascular disease. J Thorac Cardiovasc Surg. 1995;109:885-90.

20. Schachner T, Vertacnik K, Laufer G, Bonatti J. Axillary artery cannulation in surgery of the ascending aorta and the aortic arch. Eur J Cardiothorac Surg. 2002;22:445-7.

21. Svensson LG, Blackstone EH, Rajeswaran J, Sabik JF III, Lytle BW, GonzalezStawinski G, et al. Does the arterial cannulation site for circulatory arrest influence stroke risk? Ann Thorac Surg. 2004;78:1274-84.

22. Etz CD, Plestis KA, Kari FA, Silovitz D, Bodian CA, Spielvogel D, et al. Axillary cannulation significantly improves survival and neurologic outcome after atherosclerotic aneurysm repair of the aortic root and ascending aorta. Ann Thorac Surg. 2008;86:441-6.

23. Haldenwang PL, Wahlers T, Himmels A, Wippermann J, Zeriouh M, Kröner A, et al. Evaluation of risk factors for transient neurological dysfunction and adverse outcome after repair of acute type A aortic dissection in 122 consecutive patients. Eur J Cardiothorac Surg. 2012;42:e115-20.

24. Rylski B, Czerny M, Beyersdorf F, Kari FA, Siepe M, Adachi H, et al. Is right axillary artery cannulation safe in type A aortic dissection with involvement of the innominate artery? J Thorac Cardiovasc Surg. 2016;152:801-7.

25. Wada H, Sakata N, Tashiro T. Clinicopathological study on penetrating atherosclerotic ulcers and aortic dissection: distinct pattern of development of initial event. Heart Vessels. 2016;31:1855-61.

26. Hedberg M, Engström KG. Stroke after cardiac surgery-hemispheric distribution and survival. Scand Cardiovasc J. 2013;47:136-44.

27. Messé SR, Acker MA, Kasner SE, Fanning M, Giovannetti T, Ratcliffe S, et al. Stroke after aortic valve surgery: results from a prospective cohort. Circulation. 2014;129:2253-61.

Key Words: axillary artery, open arch repair, stroke 


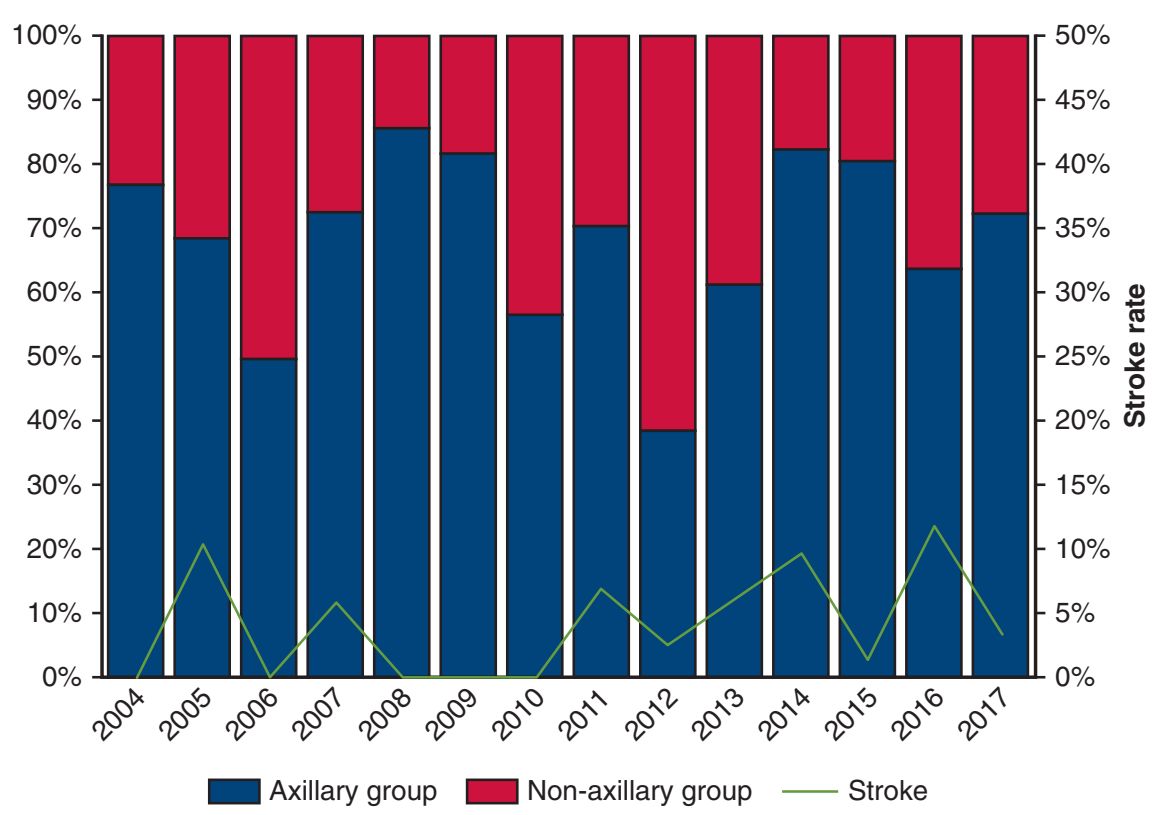

FIGURE E1. Trend of cannulation strategy and stroke rate over time. 
Distribution of Propensity Scores

Unmatched Treatment Units

Matched Treatment Units

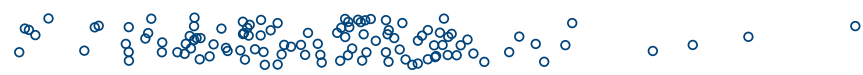

Matched Control Units

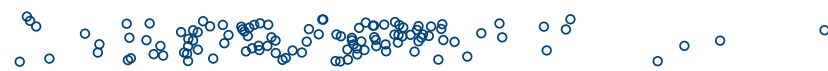

Unmatched Control Units

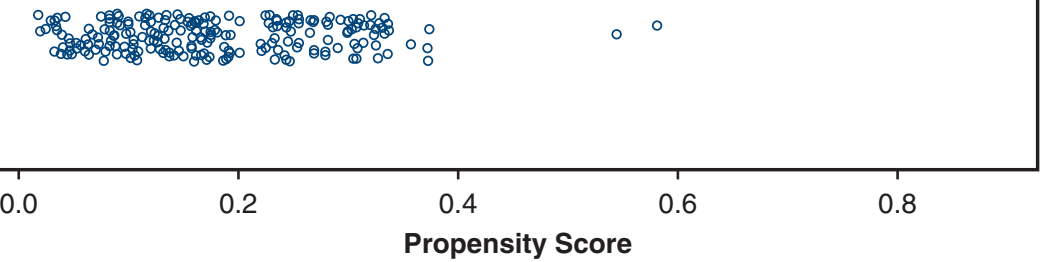

A

Raw Treated

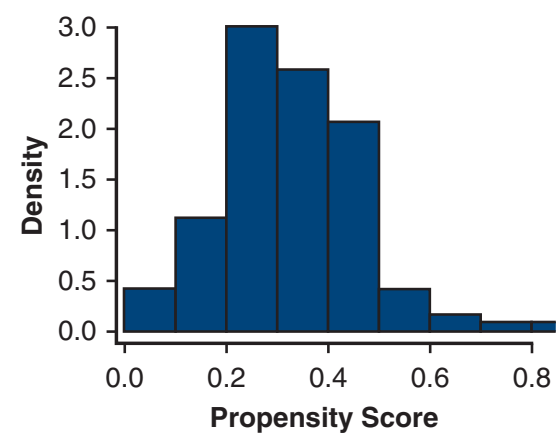

Raw Control

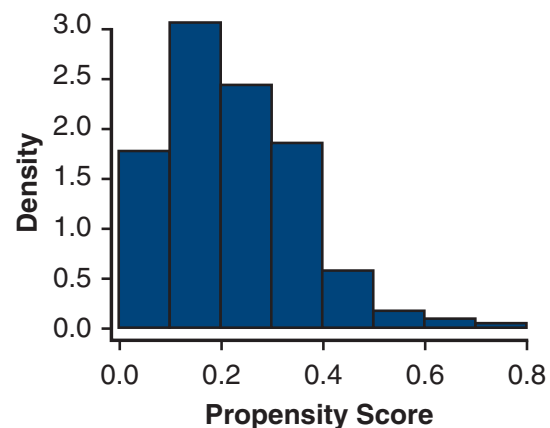

Matched Treated

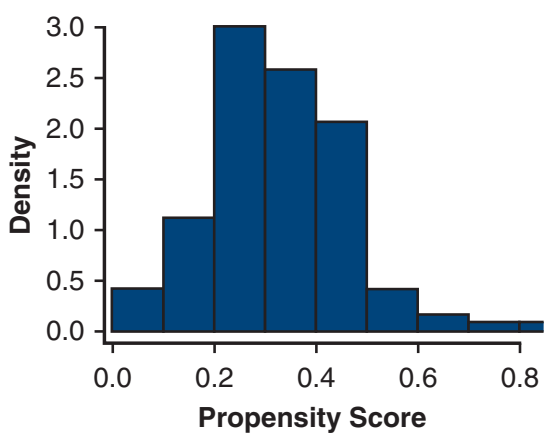

Matched Control

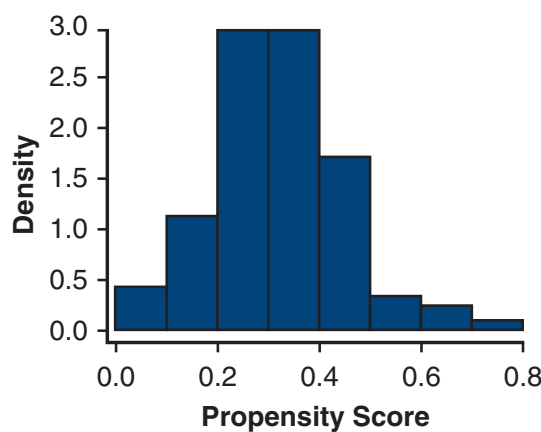

FIGURE E2. A, Distribution of propensity scores. B, Histogram of propensity scores before and after matching showed that the matched groups were well balanced and calibrated. The following factors were used for propensity score analysis: age; sex; body surface area; presence of hypertension, diabetes mellitus, cerebrovascular accident, chronic obstructive pulmonary disease, peripheral artery occlusive disease, coronary occlusive disease, dyslipidemia, carotid disease, previous open heart surgery history, Marfan syndrome, electrocardiogram, chronic kidney disease or dialysis; acute type A dissection or chronic aneurysm; shock; rupture; Debakey type; ascending aorta or arch diameter; emergency operation; date of surgery; and degree of left ventricular impairment. 


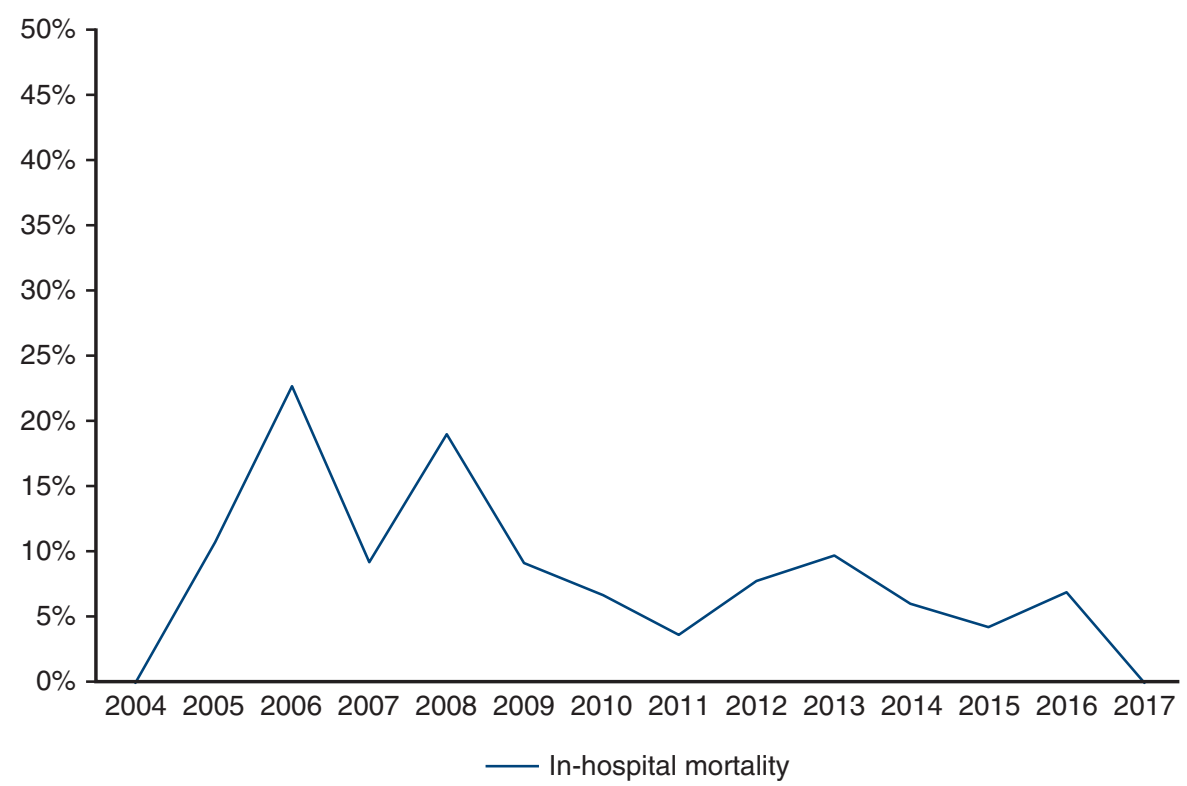

FIGURE E3. Trend of in-hospital mortality over time. In-hospital mortality tended to decrease over time. 
TABLE E1. Baseline characteristics in the unmatched population

\begin{tabular}{|c|c|c|c|c|}
\hline \multirow[b]{2}{*}{ Variable } & \multicolumn{4}{|c|}{ Unmatched population } \\
\hline & $\overline{\text { Axillary group }(n=352)}$ & Nonaxillary group $(\mathrm{n}=116)$ & $P$ value & SMD \\
\hline Age $(y)$ & $65.0(54.0-73.0)$ & $62.5(51.3-71.0)$ & .128 & 0.172 \\
\hline Male & $199(56.5)$ & $63(54.3)$ & .649 & 0.049 \\
\hline $\operatorname{BSA}\left(\mathrm{m}^{2}\right)$ & $1.71(1.56-1.85)$ & $1.72(1.60-1.86)$ & .545 & 0.039 \\
\hline HTN & $248(70.5)$ & $70(60.3)$ & .043 & 0.214 \\
\hline DM & $37(10.5)$ & $12(10.3)$ & .938 & 0.008 \\
\hline CKD & 77 (21.9) & $18(15.5)$ & .130 & 0.168 \\
\hline Dialysis & $8(2.3)$ & $2(1.7)$ & .715 & 0.040 \\
\hline Dyslipidemia & $24(6.8)$ & $4(3.4)$ & .179 & 0.155 \\
\hline CVA & $39(11.1)$ & $15(12.9)$ & .549 & 0.063 \\
\hline CAOD & $87(24.7)$ & $17(14.7)$ & .025 & 0.253 \\
\hline COPD & $54(15.3)$ & $10(8.6)$ & .063 & 0.211 \\
\hline PAOD & $15(4.3)$ & $2(1.7)$ & .201 & 0.151 \\
\hline Carotid disease & $45(12.8)$ & $14(12.1)$ & .817 & 0.025 \\
\hline Previous OHS & $37(10.5)$ & $10(8.6)$ & .540 & 0.067 \\
\hline Marfan SD & $16(4.5)$ & $5(4.3)$ & .902 & 0.013 \\
\hline EKG & & & .564 & 0.053 \\
\hline Sinus & $325(92.3)$ & $110(94.8)$ & & \\
\hline Afib & $23(6.5)$ & $4(3.4)$ & & \\
\hline PM & $4(1.1)$ & $2(1.7)$ & & \\
\hline Acute TAD & $134(38.1)$ & $43(37.1)$ & .928 & 0.010 \\
\hline Chronic aneurysm & 218 (61.9) & $75(64.7)$ & .928 & 0.010 \\
\hline Atherosclerosis & $184(84.4)$ & $61(81.3)$ & .412 & 0.081 \\
\hline Postdissection & $34(15.6)$ & 14 (18.7) & .412 & 0.081 \\
\hline Shock & $14(4.0)$ & $13(11.2)$ & .004 & 0.273 \\
\hline Rupture & $11(3.1)$ & $7(6.0)$ & .163 & 0.138 \\
\hline DeBakey type & & & $<.001$ & 0.407 \\
\hline I & $198(56.3)$ & $42(36.2)$ & & \\
\hline II & $154(43.8)$ & $74(63.8)$ & & \\
\hline AA diameter $(\mathrm{mm})$ & $52.0(45.5-57.0)$ & $51.5(47.0-57.8)$ & .997 & 0.035 \\
\hline Arch diameter (mm) & $42.0(37.0-50.0)$ & $40.0(34.0-44.0)$ & $<.001$ & 0.392 \\
\hline $\operatorname{LVEF}(\%)$ & $63.0(58.0-68.0)$ & $61.0(58.0-67.0)$ & .377 & 0.094 \\
\hline Surgery year & & & .413 & 0.068 \\
\hline 2004-2009 & $84(23.8)$ & $28(24.1)$ & & \\
\hline 2010-2014 & $112(32.1)$ & $30(25.9)$ & & \\
\hline 2015-2017 & $154(44.1)$ & $58(50.0)$ & & \\
\hline
\end{tabular}

Values for continuous variables are presented as median (interquartile range) and values for categorical variables are presented as $\mathrm{n}(\%)$. SMD, Standardized mean difference; $B S A$, body surface area; $H T N$, hypertension; $D M$, diabetes mellitus; $C K D$, chronic kidney disease; $C V A$, cerebrovascular accident; $C A O D$, coronary artery occlusive disease; $C O P D$, chronic obstructive pulmonary disease; $P A O D$, peripheral artery occlusive disease; $O H S$, open heart surgery; $S D$, syndrome; $E K G$, electrocardiogram; $A f i b$, atrial fibrillation; $P M$, pacemaker; $T A D$, type A dissection; $A A$, ascending aorta; $L V E F$, left ventricular ejection fraction. 